\title{
Principles for the Design of Business Dictionaries on Mobile Applications
}

\begin{abstract}
The rapid growth of mobile applications for smartphones in the past few years has encouraged dictionary publishers to offer mobile dictionaries. One of the most prominent target markets of mobile dictionary applications is business people, especially those who are non-native speakers of English. These business people often need a dictionary to help them understand the international news they are reading. However, as shown in the review of the current mobile business dictionaries, the dictionary applications have not taken into account the needs of the users and the technological features of smartphones. The current mobile dictionaries still resemble either their electronic versions or even worse their printed versions. This can be due to the lack of research and emphasis on the theoretical aspects of mobile lexicography. Therefore, this paper tries to formulate principles for the design of business dictionaries for mobile applications. The discussion considers the implementation of the modern theory of lexicographical functions in order to create mobile dictionaries which can better satisfy the needs of the users. The principles created are organized into two parts, they are, business news with a built-in dictionary and a dictionary with updated business news.
\end{abstract}

\section{Introduction}

A few years ago, when there was a high demand on internet dictionaries, a number of lexicographers converted their dictionaries into internet dictionaries with different extent of adjustments. Some online dictionaries are only created based on their printed versions with barely any adjustments, and some others use too many adjustments or technological features (Kwary 2010: 274). Most of the internet dictionaries were created without taking into account the needs of the users, thus only a few of them can properly satisfy the needs of the users (cf. Nielsen/Mourier 2005, Kwary 2012). As people are moving to mobile applications, the demand for dictionary applications for smartphones has also increased. Unfortunately, there is a great concern that mobile dictionaries will not be able to satisfy the needs of the user due to the lack of theoretical considerations when creating the dictionaries. Consequently, theoretical discussions on mobile lexicography have to be initiated in order to satisfy the needs of the growing number of users or target market of mobile dictionaries.

One of the most prominent target markets of mobile dictionary applications is business people, especially those who are non-native speakers of English. Crystal (2006: 424) stated that there are only about 400 million people who have English as their first language, while there are more than 400 and 600 million people who have English as their second and foreign languages, respectively. The business people who use English as a second or foreign language often need a dictionary that can help them understand the international news they are reading. Since these business people have started reading news using their smartphones, they need dictionaries which can be installed in the operating system of their mobile phones.

There are five major smartphone operating systems: iOS (iPhone), Android, BlackBerry, Windows Phone and Symbian (Nokia). From these five operating systems, Android has the biggest market share. In 2011, the market share of Android is 53\% (PC Mag 2012). Therefore, the Android market becomes the major place for business people to find applications, including mobile

\footnotetext{
* Deny A. Kwary

Airlangga University

English Department

Faculty of Humanities

Dharmawangsa Dalam Selatan, Surabaya - 60286, Indonesia

deny@kwary.net
} 
dictionary applications. Accordingly, several dictionary publishers have converted their dictionaries into Android apps which can be installed easily into smartphones. Unfortunately, as we can see later in this paper, the current mobile dictionaries are not specially designed for smartphones as they still resemble their previous versions as printed or electronic (computer) dictionaries. Obviously, they have not been created using sound theoretical foundations and they have not utilized the unique smartphone technological features.

This paper includes a theoretical discussion in formulating principles for the design of mobile dictionaries that can properly satisfy the needs of business people. The discussion is based on the modern theory of lexicographical functions which is a transformative in nature. This means that it does not only lead to improved dictionary concepts, but it also lays a solid theoretical foundation for reviews and criticism of dictionaries that do not perform their role optimally as utility tools (Tarp 2008: 84) The principles created based on this theory are organized into two parts, they are, business news with a built-in dictionary and a dictionary with updated business news.

\section{Considering the modern theory of lexicographical functions}

When creating a dictionary, we need to focus on the users, not on the publishers or on the lexicographers. This means that the design and the data available in the dictionary should be suitable for the needs of the users. This statement is in line with the modern theory of lexicographical functions. Tarp (2008: 81) defines a lexicographical function as "the satisfaction of the specific types of lexicographically relevant need that arise in a specific type of potential user in a specific type of extra-lexicographical situation." Consequently, this section starts with a discussion on the extra-lexicographical situation that gives rise to the lexicographically relevant need of the potential users.

As mentioned in the previous section, the main users or the target market of a mobile business dictionary is business people, especially those who are non-native speakers of English. A possible extra-lexicographical situation of these users is reading international business news on their smartphones. News agencies, such as Bloomberg and BBC have provided Android applications for their news, so that business people can access and read the news conveniently with their smartphones. When reading the text which is written in the English language, these business people can encounter a word, a word combination, or a multi-word expression that they do not know the meaning. This situation gives rise to the text reception need, that is, the need to understand the meaning of a word in a foreign language. This need can be satisfied by using a dictionary. These business people have a wide selection of dictionary formats: printed, computer (offline, CD-installed), internet (online), or mobile. In terms of convenience, the first three formats are not as convenient as the last one. A printed dictionary is not always available, especially when the business people are on their business trip. Opening a dictionary installed in their computers is a possible solution because business people often take their computers with them on their business trip. However, it is not convenient to open a computer while reading business news on their smartphones. Browsing an online or internet dictionary can be done with smartphones, but it means that these business people will have to open another window on their mobile phones and the internet access can be quite slow in some countries if there is more than one window is opened. Therefore, the most convenient dictionary format to access in this situation is a mobile dictionary.

After we know the user situation and the need of these business people, we also need to know the profile of these business people so that we can provide lexicographical solutions which are tailored to the situation, need, and profile of the users. The profile of the users can be related to their competence in the English language and in the business field. If we see the comparison between the number of people who have English as their first, second, and foreign languages, that is, 400 million, 400 million, and 600 million, respectively (Crystal 2006), we can assume that the main target market consists of people who have English as their second or foreign language. The business people from this group usually have English language competence at the intermediate level. Therefore, they can either use a monolingual or a bilingual dictionary. A monolingual dictionary 
is usually intended for advanced learners, while a bilingual dictionary is usually aimed at learners at the beginner level. However, several scholars (e.g. Koren 1997, Nation 2001) have mentioned the general preference of non-native speakers of English for consulting bilingual dictionaries over monolingual dictionaries. The selection of dictionaries based on the language is sometimes exaggerated. The important aspect should not be on what language to be used but on how suitable the definition is for the encyclopaedic competence. Several scholars (e.g. Bergenholtz/Nielsen 2006, Kwary 2011) have shown that people who have different levels of subject-field competence (experts, semi-experts, and laypeople) should be provided with different types of definitions. For mobile business dictionaries, a semi-expert definition should be provided. Business people who need the dictionaries are not laypeople in business. They are not experts either, because as Bergenholtz/Kaufmann (1997: 102) stated, experts in the particular subject field will not have text reception problems.

After we identify the extra-lexicographical situation that gives rise to the need of a dictionary of the specific user group, we shall see how the current mobile business dictionaries have tried to fulfil the demand on mobiles dictionaries but are scarcely successful in satisfying the specific need of this potential user group.

\section{Reviewing the current business dictionaries on smartphones}

As mentioned in the previous section, business people may need to use dictionaries when reading international news that are written in English. In such a situation, they would prefer consulting a mobile dictionary instead of other types of dictionary formats. These other types of dictionary formats can be used as the basis to make the mobile dictionaries. However, since smartphones have relatively small screens and different technological capabilities, some adjustments to the dictionary design should be made. Unfortunately, as we can see in the following review of the current mobile business dictionaries, lexicographers and publishers have not made the necessary adjustments of the dictionaries that they have not been able to properly satisfy the need of the users. The first mobile dictionary reviewed is the Business Dictionary, the second is Longman Business Dictionary, and the third is The Free Dictionary.

The Business Dictionary is published by ManagementMania, which advertises itself as "a single stop, all-in-one business-to-business internet portal offering comprehensive, practical and reliable business information as well as related products and services" (ManagementMania 2012). In the description of the dictionary, we can find the following information: "Understand and learn more than 2000 business terms. Increase your knowledge with Free Business Dictionary from ManagementMania.com. Business Dictionary includes a lot of different terms from variety of fields used in common practice" (https://play.google.com/store accessed on 10 September 2012). The screenshots of the dictionary can be seen in Figure 1. 


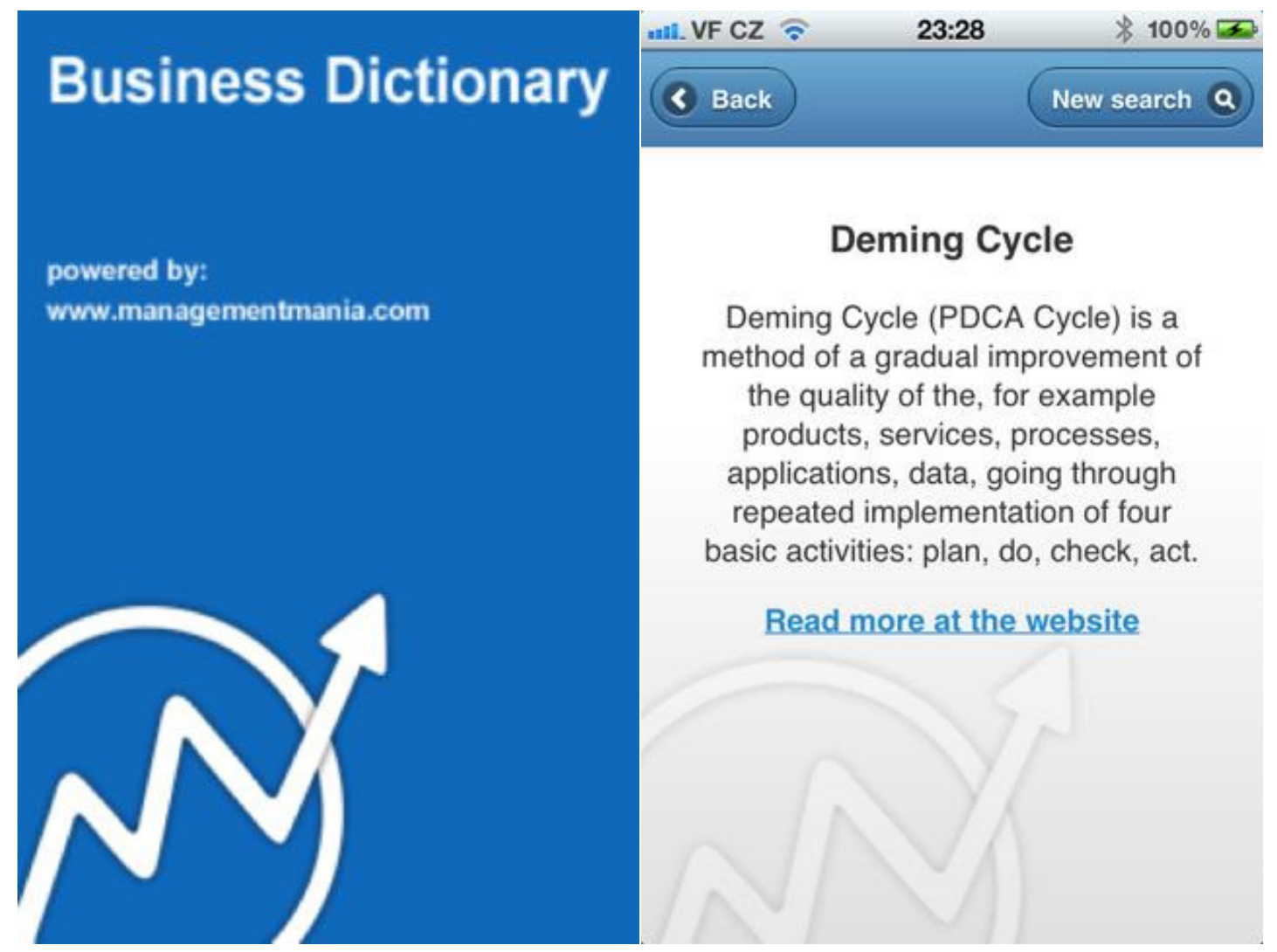

Figure 1. The screenshots of the Business Dictionary

The Business Dictionary is an example of a mobile dictionary which largely resembles a printed dictionary. When we open the dictionary, we will be shown with the cover of the dictionary for a few seconds, and then we will automatically be directed to the search box in which we can type in the word or the term we want to look for. However, after we type in a term, we are not directed directly to the definition of the term. Instead, we are directed to the related terms. For example, if we type the term deeming cycle, the dictionary will show a list containing three terms, they are deeming cycle, innovation management, and management methods, and the user will need to click on one of the terms to see the definition. The lexicographer of this dictionary might assume that when a user is looking for the term deeming cycle, this user may want to know the related terms as well. This assumption, however, carries a flaw because it does not consider the extra-lexicographical situation. As mentioned in the previous section, the most common situation is that a user is reading a business news text and finds a word that he does not know the meaning. Therefore, the need of this user to consult the dictionary is to find the meaning of the word, not the related words. When this user types in an exact term, such as deeming cycle, this user will expect to be presented with the definition of this term, not the related terms.

Another problem with the Business Dictionary is the small number of entries available in the dictionary, that is only about 2,000 terms. Nielsen (1994) stated that an LSP dictionary usually consists of approximately 7,000 entries. Therefore, the number of entries in the Business Dictionary is far below the general standard of an LSP dictionary. If we take into account the dictionary function, that is for text reception, the number of entries should even be larger. Business people may need to consult a dictionary, not only to find the meanings of business terms, but also other difficult words which are not related to business but are used in a text. For example, consider the following headline of The Wall Street Journal on 20 September 2012: Bank of America Ramps Up Job Cuts. The word ramp is not a business term but it may cause a text reception problem. There- 
fore, a good text reception dictionary should include this word in the entries. This also means that boundaries between general and specialised dictionaries should disappear.

The second dictionary, Longman Business Dictionary produced by Pearson Education Ltd, contains a lot more entries than the Business Dictionary. In the product description of Longman Business Dictionary we can find the information that the dictionary contains over 30,000 words and phrases. The screenshots of this dictionary can be seen in Figure 2.

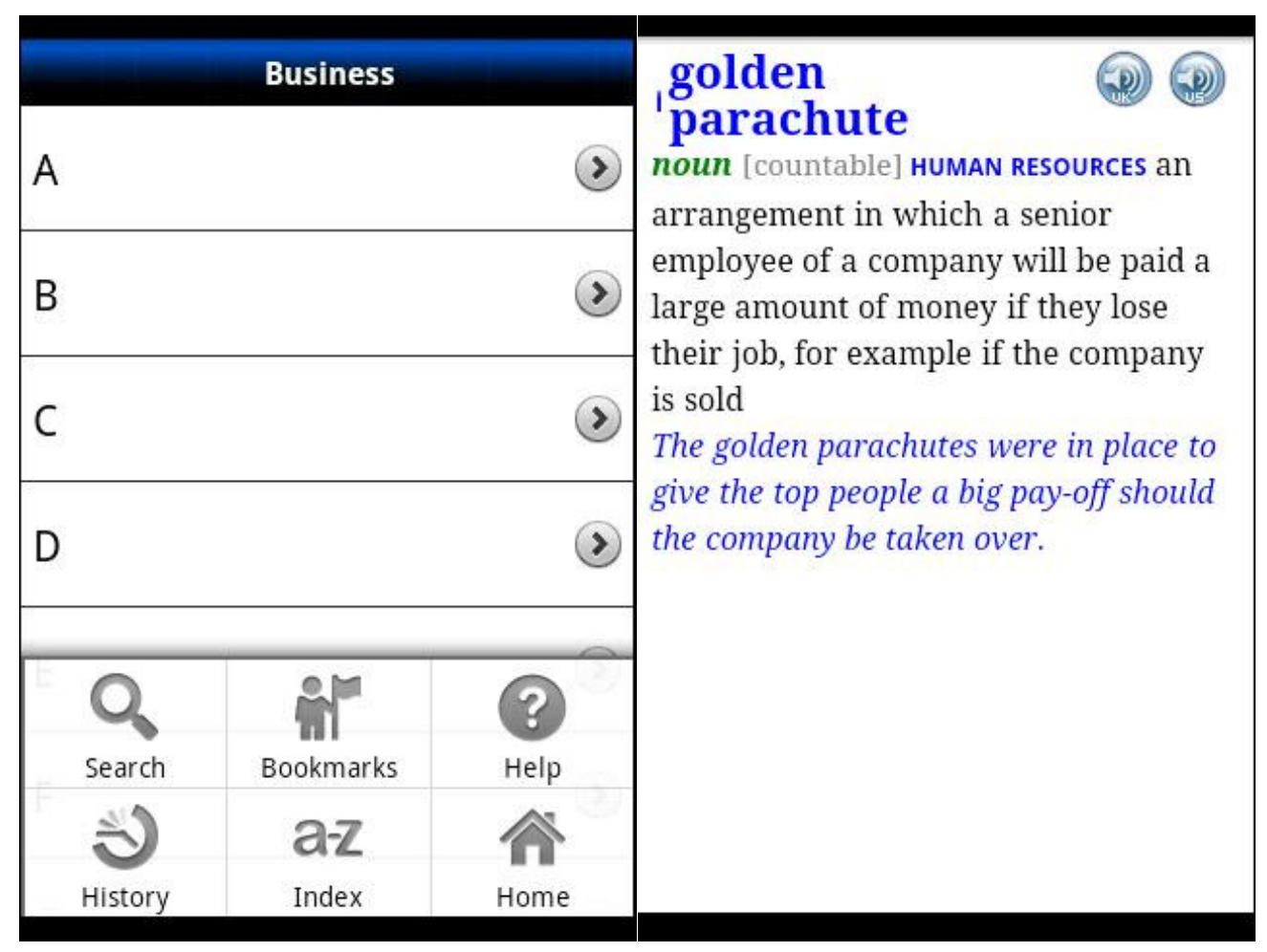

Figure 2. The screenshots of Longman Business Dictionary

The mobile application version of Longman Business Dictionary is based on the printed and CD version of the dictionary published in 2007. This mobile dictionary application is not a freeware. It costs USD22.37 (https://play.google.com/store accessed on 10 September 2012), which is very expensive for a mobile application. Therefore, the number of installs per 10 September 2012 was only at the range of 100-500. As a comparison, the number of installs for the Business Dictionary was at the range of 5,000 to 10,000 .

As we can see in the example of the dictionary entry in Figure 2, the information available in Longman Business Dictionary is more extensive than that available in the Business Dictionary. However, some of the information is not useful for text reception. For example, the speaker icons on the right hand top which refer to the pronunciation of the term in UK and US, are not necessary for a text reception dictionary. A user will not understand more about the meaning of a word by listening to its pronunciation. This mobile application large resembles its CD version. The lexicographer or the publisher has not considered the need of the business people and the fact that smartphones have smaller screens than computers. Therefore, some adjustments to the CD version have to be made so that the dictionary can satisfy the need of the users properly.

The third dictionary, The Free Dictionary produced by Farlex, is a collection of dictionaries which include a business dictionary. Therefore, it is very popular among smartphone users. The number of installs per 10 September 2012 was at the range of $1,000,000-5,000,000$, and it is available for free. The screenshots of this dictionary are presented in Figure 3. 


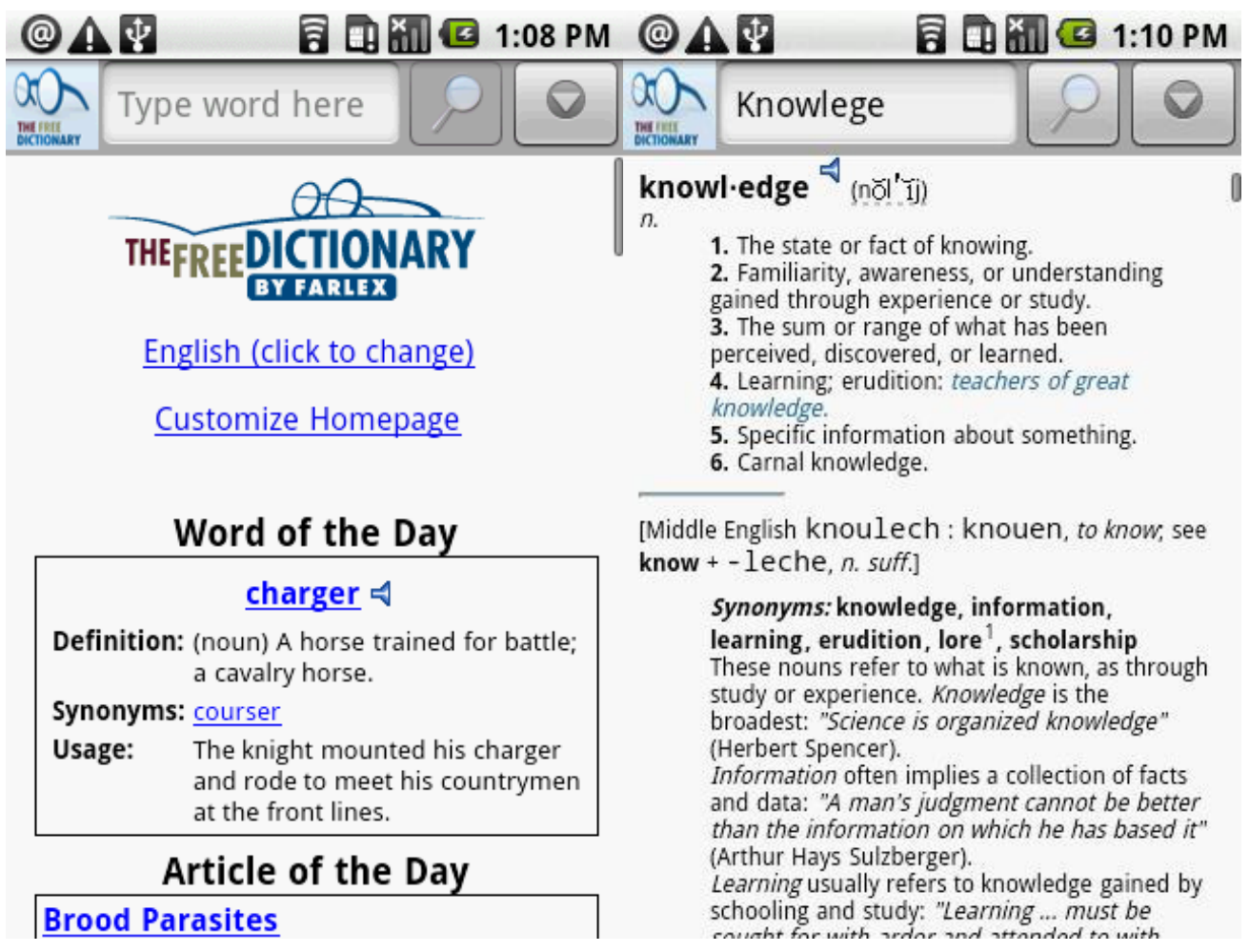

Figure 3. The screenshots of The Free Dictionary

The Free Dictionary is an example of a mobile dictionary application that utilizes the technological features extravagantly. As we can see in Figure 3, the first page of the dictionary does not only contain the search box, but also other links, they are: Word of the Day, Article of the Day, Quote of the Day, This Day in History, Today's Birthday, In the News, Weather, Hangman (game), Spelling Bee, Words within Words (game), Horoscope, and Match Up (game). The publisher of this dictionary might want to show that the dictionary can be used as an entertainment. Therefore, there are games and links which are not related to the main functions of a dictionary.

The Free Dictionary can be an option to consult when reading a business news text, but the information available is too excessive and remotely related to the need of business people. This mobile dictionary is similar to the Internet version of the dictionary. One of the Internet dictionaries available in The Free Dictionary, that is the Financial Dictionary, has been reviewed by Kwary (2010) in which the result of the review shows that its extravagant technological features are mostly unhelpful to satisfy the need of the users. For example, the ability of the dictionary to present more than one dictionary entry from several dictionaries only incurs high Content Related Information Cost (the term initially used by Nielsen 2008). Business people who are using a mobile dictionary application need to access the definition and understand the meaning of a term in the quickest and easiest way. They normally do not want to be presented with excessive information that only makes them confused.

According to the review of the three mobile dictionaries, we can conclude that none of them has been able to properly satisfy the need of the users. These mobile dictionaries were created without thorough considerations on the main need of smartphone users and the unique design and features of smartphones. The Business Dictionary largely resembles a printed dictionary, Longman Business Dictionary is a copy of its CD version, and The Free Dictionary is identical with its Internet version. Business people, who are consulting a mobile dictionary application, have a special need and should be provided with a tool specially designed to satisfy their specific need properly. 


\section{Towards the Future Mobile Business Dictionaries}

As technology evolves, dictionary should also evolve. Most of the traditional definitions of a dictionary are no longer applicable particularly in connection with the recent advances in lexicography. The following are examples of traditional definitions of a dictionary which are found in the Oxford Advanced Learner's Dictionary (2010):

1. a book that gives a list of the words of a language in alphabetical order and explains what they mean, or gives a word for them in a foreign language a Spanish-English dictionary

2. a book that explains the words that are used in a particular subject a dictionary of mathematics

3. a list of words in electronic form, for example stored in a computer's spellchecker

None of the above definitions can be applied to a mobile dictionary that takes into account the technological features and the needs of the users. A mobile dictionary is definitely not a book and the dictionary should go beyond merely a list of words. A dictionary should be considered as a tool that provides solutions to lexicographical problems. We should not confine our thinking with the traditional definitions of a dictionary. This section proposes two forms of mobile business dictionaries that integrate the mobile technology features with the needs of the users.

\subsection{Business News with a Built-In Dictionary}

Business people often live in a hectic life where quick, easy, and correct solutions to their problems are always preferred. A dictionary that is suitable for business people is a dictionary that provides quick, easy, and correct answers to their lexicographical problems. Therefore, the access process to a dictionary is more important than the medium of the dictionary, as Bergenholtz/Gouws (2010: 103) eloquently state:

Access should not be seen from the perspective of the lexicographer but empirical data and theoretical considerations should be employed to determine the real access real users of real reference sources have to real data in order to retrieve the required information as quickly and as successfully as possible. The medium of the reference source (dictionary, text book, manual, etc.) is not important. What is important is to create a situation where the required data is accessible and can be found in the quickest possible time.

In designing a mobile dictionary, the lexicographer should consider the user situation and provide the quickest access to the required information or the real need of the user. One typical user situation of mobile business dictionary user is reading a business text, for example the following headline in the Bloomberg Business Week on 23 September 2012: "Aussie Debacle Signaling China Hard Landing as Iron Market Melts." When reading this text, a user may have a problem in understanding the meaning of the word debacle. To find the meaning of this word, the user may consult a mobile dictionary. However, the user has to close or minimize the text window first, to open the mobile dictionary. In this case, another problem may emerge. The user may forget the exact spelling of the word, so he will need to reopen the business news window, and return to the dictionary window again.

In order to provide the solutions to the lexicographical problems of business people as quick and as successful as possible, the business news should be integrated with a built-in dictionary which should include at least two languages, for example English as an International language and Indonesian as a language that has a big number of speakers. The built-in dictionary will automatically read and link all the English words in the news to certain parts of the dictionary. There are at least two links to be provided. The first link is from the English words in the business text to the Indonesian equivalents. If the equivalents are not available, the link will go to the English definitions. If it is not available in the English definitions either, the link will go to a Google search. 
The second link is from the equivalent to the full dictionary entries. The illustration of the situation is presented in the following paragraphs.

As in the previous example, a user would like to know the meaning of the word debacle in the business news he is reading. Given the touchscreen technology of smartphones, the user should be able to simply touch or tap the word debacle for two seconds and the word will be highlighted and the meaning or the equivalent of the word will pop-up in the same window or screen automatically. This concept is similar to the concept of tooltips in an Internet dictionary where a user can click or hover the cursor or the pointer over a term and a small pop-up window will float near the term and show its equivalent (See Kwary 2012: 18). However, for smartphones, it is more common to use the touchscreen technology instead of using a cursor or a pointer. Therefore, for a smartphone, a tooltip showing the meaning of a word is triggered by touching to the word on the screen instead of by clicking or hovering a cursor over the word. After the user sees the meaning of the word, the user just needs to touch the meaning for one second and the pop-up window will close. The illustration of this situation is shown in Figure 4.

The availability of a built-in dictionary embedded in business news will ensure a quick and successful access to the dictionary. This will also eliminate the problems related to the spelling and the opening of a new window. The situation shown in Figure 4 is for an Indonesian user, so the tooltip shows the Indonesian equivalent of the English word debacle. As mentioned in Section 2, business people who are non-native speakers of English usually have an English language competence at the intermediate level. Therefore, presenting the equivalent can be a good option to solve their text reception problem.

Bloomberg Businessweek

September 23, 2012

Aussie Debacle Signaling

China Hard Landing as Iron

Market Melts

From the end of 2008 through

July, no major currency

appreciated as much as

Australia's dollar, thanks to

booming shipments of iron ore

and other commodities to China.

Since then, it's the worst

performer as the engine of world growth slows.

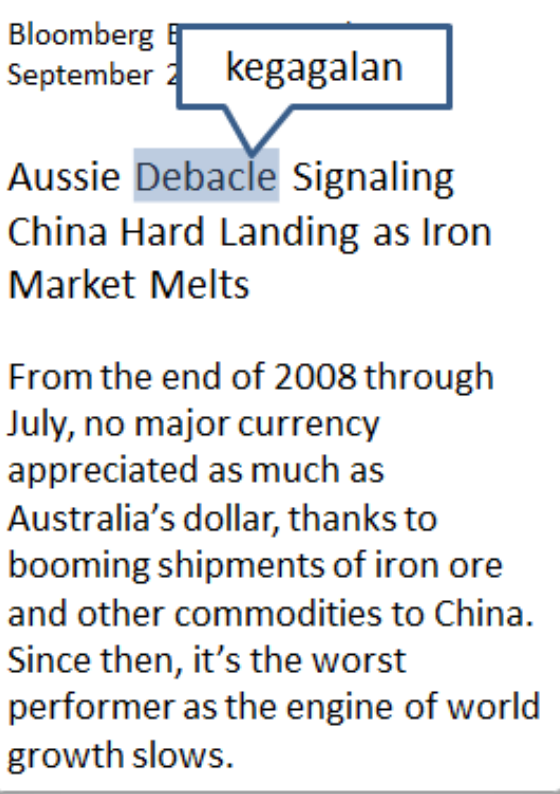

Figure 4. Business News with a Built-In Dictionary

The word debacle in the example is a single sense word. Therefore, it is easy to present only one Indonesian equivalent for the English word. The case is different when we consider a word that has more than one sense, thus more than one equivalent. In this case, the dictionary should present the most common equivalent in business field first. For example, in the text in Figure 4, we can see the word currency. This word has two senses and thus two Indonesian equivalents: keberterimaan 'accepted and popular at the moment' and mata uang 'money system of a country'. When the word currency is touched by the user, only the equivalent mata uang is shown. This can 
be realized by ordering the senses in which the sense related to business is put first before a more general sense.

In some cases, a word or a term can have more than two equivalents, and the equivalent shown in the tooltip may not be the appropriate one for the particular context. In such cases, the concept of a tooltip explained earlier should then be extended, not only for showing the meaning but also for linking it to the dictionary entry. Consequently, when a user only touches the equivalent for a second, the tooltip will close, but when the user touches the equivalent for two seconds, the full dictionary entry will be shown in the second half of the screen. This means that the screen of the smartphone will be divided into two parts: the first part is the business text and the second part is the dictionary entry. The divider between the part of the business text and the part of the dictionary entry should be able to be moved up and down with a finger touch, so the users can adjust the view as they like (See Figure 5). The users can also click on the link (set language) to change the equivalent to another language. In Figure 5, it is the Indonesian equivalent presented.

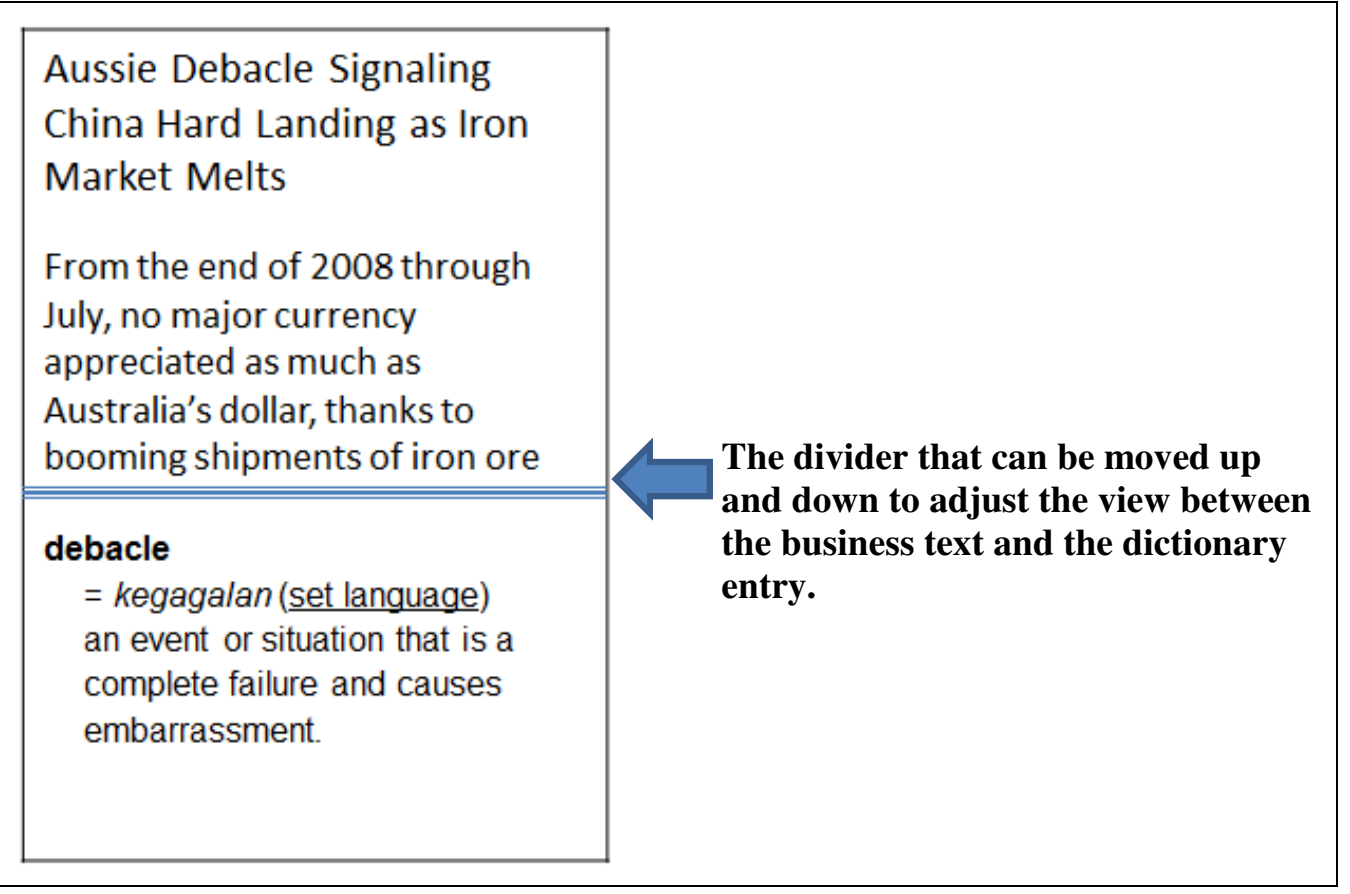

Figure 5. The Business Text and the Dictionary Entry

The selection of the language used for the equivalents can be set manually by the users or automatically by using the GPS (Global Positioning System). A smartphone is equipped with a GPS that allows the detection of the exact location of its user. Therefore, a user whose geographical coordinates show that he is in Indonesia will automatically be presented with the Indonesian equivalents of the English words. When this user goes to another country, he should set the equivalents manually. For example, if this Indonesian business person is on a business trip to Denmark, the automatic setting with the GPS will present the equivalents in the local language, that is Danish. This is not useful for this user as he is not Danish. Therefore, he has to set it manually so that he is presented with the Indonesian equivalents of the English terms.

As explained above, the automatic setting enables the built-in dictionary to present the local language equivalents of the English terms. However, considering the big number of languages in the world, it is over-ambitious to expect the built-in dictionary to include all the native languages of all the business people in the world.. When the native or local language is not available, the built-in dictionary will present the English definitions of the English terms. Alternatively, the user can select the language that he is familiar with. For example, if the built-in dictionary does not 
have the Norwegian language, a Norwegian user may select the Danish language (assuming that this is available in the dictionary). In this case, this user will be presented with the Danish equivalents of the English terms.

If we take a closer look at the dictionary entry in Figure 5, we might think that it is a semi-bilingual dictionary. It is semi-bilingual in the sense that the headword is explained by using two languages, so there are the English definition and the Indonesian equivalent. However, the concept and thus the purpose are actually different. In semi-bilingual dictionaries, such as those developed by Kernerman since the 1980 s, the definition is presented before the equivalent. The purpose is to encourage the users to read the Second Language or English definition first before looking at the equivalent in their native language. This concept is believed to help the users in learning English because they are more exposed to the English language. However, for a mobile business dictionary, the users do not consult the dictionary to help them learn English, but to help them solve their text reception problem. Therefore, it is the native language equivalent which is presented first before the English definition.

The dictionary entry in Figure 5 is a simple example where the business term is a single-word unit. A further technological feature should be included in the business text when dealing with multi-word units. In this case, the built-in dictionary should always identify the multi-word units when creating the links to the dictionary entries. To illustrate this, take for example a situation where a business person is reading the following text from The Wall Street Journal on 23 September 2012: "Others predict that, as most Italian lenders trade well below their book value, their shares can rise in step with their assets even if operating profits remain tepid." If this user wants to find the meaning of the term book value, he can either touch the word book or value. The builtin dictionary should be able to identify the nearby word(s) and to link the search with the longest entry in the dictionary. In this case, the entries of the dictionary may contain single words, multiword expressions and other word combinations. Therefore, when the user touches the word book for two seconds, the built-in dictionary will read the nearby words, i.e. ' ... below their book value, their shares...'. The program will direct the search result to the longest entry available in the dictionary. Therefore, the equivalent or the dictionary entry presented is not for the word book, but for the term book value.

The same technological feature should also be applied to phrasal verbs and other fixed expressions. For example, the text mentioned in Section 3, which is taken from The Wall Street Journal on 20 September 2012: Bank of America Ramps Up Job Cuts. When a user touches the word ramp, the dictionary will read the nearby words as well, and direct the result to the phrasal verb ramp up instead of the verb or the noun ramp. This is important because in the English language, the meanings of the phrases are often different from the meanings of the individual words.

In order to have business news with a built-in dictionary, it is necessary to establish a mutual collaboration between a business news agency and a business dictionary. One possible collaboration is between Bloomberg and Farlex. Bloomberg has an Android application for smartphones that provides access to business news and the news are regularly updated. Farlex has an Android application called The Free Dictionary which contains a number of dictionaries, including bilingual dictionaries covering more than 20 languages. Another possibility is the collaboration between Google Finance and Google Dictionary. However, adjustments as mentioned in the previous paragraphs should be made in order to properly satisfy the need of the users and to provide the quickest and easiest access to the dictionary. The phrase 'simple and easy' that has become the catchphrase for mobile UI (user interface) design (Choi/Lee 2012), should always be taken into account by lexicographers who want to design a mobile dictionary application.

\subsection{A Dictionary with Updated Business News}

In addition to integrating a dictionary into business news, as explained in the previous sub-section, it will also be useful to conduct the other way around, that is to integrate business news into 
a dictionary. This will extend the function of a dictionary from its traditional senses, and make a dictionary as a resourceful information tool. A similar integration has actually been applied by The Free Dictionary, but the integration is too extravagant that it is scarcely useful for business people.

When a user opens the mobile application of The Free Dictionary in his smartphone, he will be presented with several features. In Figure 3, The Free Dictionary presents the Word of the Day and the Article of the Day. If we scroll down the screen, we can find several more features, including games. If the dictionary is intended for business people, the important feature to include is the Latest Business Headlines. The illustration of the user situation is explained in the following paragraphs.

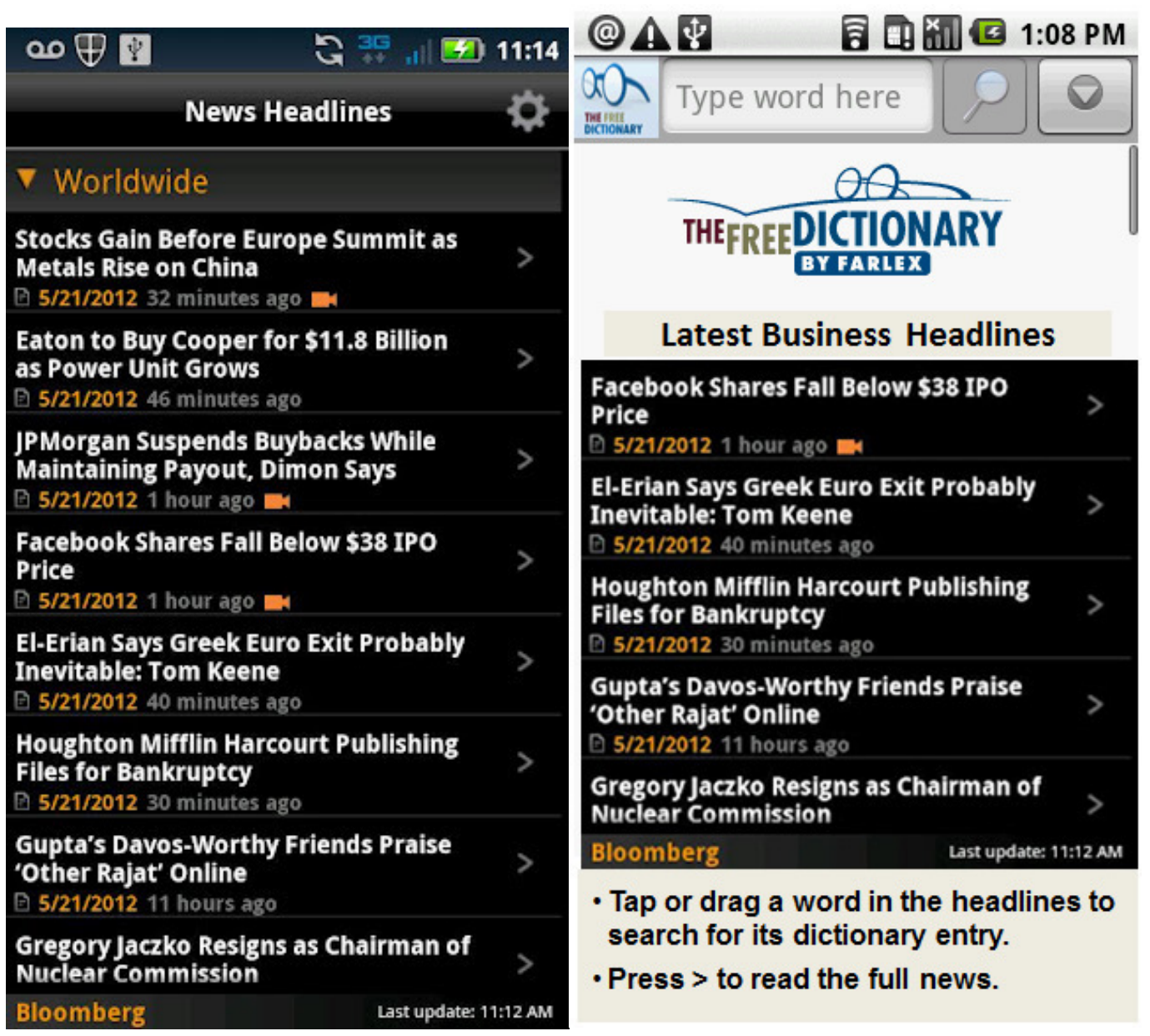

Figure 6. The screenshots Blomberg for Smartphone and the Proposed Modification

The picture on the left in Figure 6 is the screenshot of Bloomberg for Smartphone application. This is a popular application with the number of installs per 10 September 2012 was at the range of $1,000,000$ to $5,000,000$. In the description of this mobile application, we can find the following information: Get comprehensive news coverage along with easy-to-understand charts and graphs that illustrate the impact of important business trends and issues." (https://play.google.com/store accessed on 10 September 2012). The charts and graphs may have been designed in a special way that they are easy to understand. However, some of the business news may be incomprehensible to the users especially the business people who are non-native speakers of English. Therefore, it is necessary to provide a tool, that is a dictionary, to assist the users in the text reception situation. 
The proposed modification to the Bloomberg smartphone application and The Free Dictionary smartphone application is shown in the picture on the right in Figure 6. Consequently, when the users want to know the meaning of a particular word, they can either tap or drag the word to the search box on the top of the screen. The users can also type in the word in the search box. However, the touchscreen technology in smartphones will make the access easier and eliminate the problems related to a typo when typing the word. The divider explained in the previous sub-section (see Figure 5) can also be used here to divide the screen into two when the dictionary entry is shown. However, in this case, the dictionary entry is on the upper part of the screen, and the business headlines or news are placed at the lower part of the screen.

The mobile dictionary does not have to depend on one company or business news provider to present the latest business news. The mobile dictionary can harvest the business news from a search engine like Google or from other sources, so that the business people who use this mobile dictionary can get a variety of information from different sources. A mobile dictionary which is embedded with updated business news will become a resourceful information tool for business people. This concept extends the traditional function of a dictionary, that is to find the meanings of the words, into a reference work to find and understand business news. The users, who are business people, open the dictionary to find out the latest business news. This dictionary becomes a preferable option because it does not only provide the latest business news (as in the case of a simple business news application), but also a tool to help the users understand the business news they are reading.

\section{Conclusion}

As mobile applications for smartphones have become more popular in the recent years, dictionary publishers have also started providing dictionaries in the form of mobile applications. Unfortunately, the current dictionary applications have not been created with a solid theoretical foundation that they have not met the real needs of the users and have not utilized the unique technological features of smartphones. The three mobile dictionaries reviewed in this paper - the Business Dictionary, Longman Business Dictionary, and The Free Dictionary - largely resemble a printed dictionary, a (computer-installed) compact disk dictionary and an internet dictionary, respectively. They have not taken into account the unique technological features of smartphones and the extralexicographical situations of the business people who need to consult mobile dictionaries.

This paper proposes principles for designing business dictionaries for mobile applications, with a focus on meeting the needs of the users properly. The principles created are organized into two parts, they are, 'business news with a built-in dictionary' and 'a dictionary with updated business news'. In the 'business news with a built-in dictionary', the users do not always have to see the traditional form of the dictionary. In this case, the dictionary can be called a tooltip. However, it does not matter what it is called, as long as it can help the users to access and know the meaning of the word in the easiest way and the quickest possible time. In the concept of 'a dictionary with updated business news', the traditional function of a dictionary is extended that it becomes a resourceful information tool for business people.

\section{References}

Bergenholtz, H./Gouws, R. 2010: A new perspective on the Access Process. In Hermes. Journal of Language and Communication Studies 44, 103-127.

Bergenholtz, H./Kaufmann, U. 1997: Terminography and lexicography: A critical survey of dictionaries from a single specialised field. In Hermes. Journal of Language and Communication Studies 18, 91-125.

Bergenholtz, H./Nielsen, S. 2006: Subject-field components as integrated parts of LSP dictionaries. In Terminology, 12(2), 281-303.

Bloomberg. Bloomberg Business Week [online]. http://bloomberg.com (accessed 23 September 2012).

Choi, J. H./Lee, H.-J. 2012: Facets of Simplicity for the Smartphone Interface: A Structural Model. In International Journal of Human Computer Studies 70, 129-142. 
Crystal, D. 2006: English Worldwide. In Hogg, R/Denison, D (eds.), A History of the English Language. Cambridge: Cambridge University Press, 420-439

Farlex. The Free Dictionary [online]. https://play.google.com/store (accessed 10 September 2012).

Koren, S. 1997: Quality versus convenience: Comparison of modern dictionaries from the researcher's, teacher's and learner's points of view. In Teaching English as a Second or Foreign Language 2(3), 1-16.

Kwary, D. A. 2010: Access Routes of Internet Finance Dictionaries: Present Solutions and Future Opportunities. In Lexikos 20, 272-289.

Kwary, D. A. 2011: Towards a typology of definitions for LSP dictionaries. In Journal of English Studies 9, 73-91.

Kwary, D. A. 2012: Adaptive hypermedia and User-oriented data for online Dictionaries. In International Journal of Lexicography, 25: 1

Management Mania. Business Dictionary [online]. https://play.google.com/store (accessed 10 September 2012).

ManagementMania. About [online]. http://managementmania.com/en/about-us (accessed 10 September 2012).

Nielsen, S. 1994: The Bilingual LSP Dictionary. Principles and Practice for Legal Language. Tübingen: Gunter Narr Verlag.

Nielsen, S. and Mourier, L. 2005: Internet accounting dictionaries: Present solutions and future opportunities. In Hermes. Journal of Language and Communication Studies, 34, pp.83-116.

Nation, I. S. P. 2001: Learning Vocabulary in Another Language. Cambridge: Cambridge University Press.

Nielsen, S. 2008: The Effect of Lexicographical Information Costs on Dictionary Making and Use. In Lexikos 18: 170-189.

PC Mag [online]. http://www.pcmag.com/encyclopedia_term (accessed 8 September 2012).

Pearson Education. Longman Business Dictionary [online]. https://play.google.com/store (accessed 10 September 2012).

Tarp, S. 2008: Lexicography in the Borderland between Knowledge and Non-knowledge: General Lexicographical Theory with Particular Focus on Learner's Lexicography. Tübigen: Niemeyer.

The Wall Street Journal [online]. http://online.wsj.com/home-page (accessed 20 and 23 September 2012).

Turnbull, J. ed. 2010: Oxford Advanced Learner's Dictionary. 8th ed. Oxford: Oxford University Press. 